\title{
Tripanosomiasis americana en un canino del nordeste argentino. Reporte del caso clínico
}

\author{
Rosas, A.C..; Ojeda, G.P. ${ }^{2}$; Barrios, A. ${ }^{3}$; Otteo, M. ${ }^{4}$; Maruñak, S.L. ${ }^{5}$ \\ Cátedras de Cirugía ${ }^{1}$, Farmacología ${ }^{2}$ y Bioquímica ${ }^{5}$, Fac. Cs. Veterinarias UNNE, Cabral 2139, Corrientes \\ (3400), Argentina, Tel 3794 425753. ${ }^{3}$ Instituto de Patología Experimental, Universidad Nacional de Salta. \\ ${ }^{4}$ Veterinario, profesión libre. E-mail: patmed@vet.unne.edu.ar
}

\begin{abstract}
Resumen
Rosas, A.C.; Ojeda, G.P.; Barrios, A.; Otteo, M.; Maruñak, S.L.: Tripanosomiasis americana en un canino del nordeste argentino. Reporte del caso clínico. Rev vet 27: 1, 62-65, 2016. Se relata el hallazgo de un perro domiciliario afectado por Trypanosoma cruzi en Chaco (Argentina) en el año 2014, corroborando el importante rol de los cánidos domésticos y peridomésticos en la transmisión del Mal de Chagas. El diagnóstico fue confirmado por métodos parasitológicos (frotis), serológicos (hemoaglutinación indirecta) y moleculares (PCR). Ante casos sospechosos se enfatiza la necesidad de profundizar las técnicas diagnósticas dado que los caninos pueden constituir una fuente de infección de tripanosomiasis americana para otras especies, incluyendo seres humanos.
\end{abstract}

Palabras clave: perro, Trypanosoma cruzi, confirmación diagnóstica, nordeste argentino.

\begin{abstract}
Rosas, A.C.; Ojeda, G.P.; Barrios, A.; Otteo, M.; Maruñak, S.L.: American trypanosomiasis in a dog from Argentinean northeast. Report of the clinical case. Rev vet 27: 1, 6265, 2016. The finding of a dog affected by Trypanosoma cruzi in Chaco (Argentina) in 2014 is presented. This fact corroborates the important role of domestic and peridomestic canines in the transmission of Chagas disease. Diagnosis was corroborated by parasitological (smear), serological (indirect hemo-agglutination) and molecular (PCR) methods. For those suspicious cases of trypanosomiasis, the need of accurate diagnostic techniques is emphasized, since dogs can constitute a potential source of infection of American trypanosomiasis for other species including human beings.
\end{abstract}

Key words: dog, Trypanosoma cruzi, diagnostic confirmation, Argentina northeast.

\section{La tripanosomiasis del canino}

La tripanosomiasis americana, también llamada enfermedad de Chagas en honor a su descubridor, es una parasitosis causada por Trypanosoma cruzi, un protozoario flagelado perteneciente al orden Kinetoplastida, familia Trypanosomatidae, extensamente distribuido en el continente americano ${ }^{7,18}$. En latinoamérica la enfermedad afecta a millones de personas, causando importantes problemas sanitarios, económicos y sociales. En la actualidad constituye la cuarta enfermedad tropical más importante, sólo superada por la malaria, la tuberculosis y la esquistosomiasis ${ }^{16}$. Para enfatizar su importancia es dable tener en cuenta que el mal de Chagas es exclusivamente americano, en tanto que las restantes enfermedades son globales. En Argentina es una causa frecuente de cardiopatías ${ }^{20}$.

Recibido: 5 octubre 2015 / Aceptado: 10 febrero 2016
La afección es primariamente una enzootia y está restringida a grupos de animales silvestres, transformándose en zoonosis con el manejo y colonización de áreas deshabitadas o poco impactadas, cuando hombres, animales domésticos y/o sinantrópicos se integran a la cadena de transmisión ${ }^{2,9}$. T. cruzi desarrolla su ciclo de vida en ocho órdenes de mamíferos y en más de 140 especies de insectos estrictamente hematófagos, siendo la "vinchuca" (Triatoma infestans) el vector de mayor importancia epidemiológica en Argentina 4,9.

De acuerdo a los mamíferos intervinientes puede definirse un ciclo doméstico-peridoméstico, cuando intervienen el hombre y animales como el perro y el gato, o un ciclo selvático cuando se involucran marsupiales, edentados, quirópteros, carnívoros y roedores silvestres ${ }^{15}$. Se ha considerado que el perro juega un papel muy importante en la transmisión de $T$. cruzi domiciliar, constituyendo un nexo entre los ambientes domésticos, peridomésticos y selváticos, dado sus hábitos 
de caza para alimentarse, su estricta convivencia con el hombre y la alta capacidad infectante del vector ${ }^{10}$.

En el norte argentino los caninos son importantes reservorios domésticos de $T$. $c r u z i^{8}$. En áreas rurales ellos revelan prevalencias de hasta el $49 \%{ }^{14}$ y en el noroeste se registró una seropositividad para $T$. cruzi de $28,2 \%(8 / 39)^{5}$. Además de la vía clásica a partir de vectores parasitados, la transmisión oral en las especies animales representa un mecanismo mucho más efectivo, cuando -por instinto- el perro toma el insecto con la boca y lo mastica, conjuntamente con la acción de lamer superficies contaminadas ${ }^{4,19}$.

Se ha estimado que los animales son catorce veces más efectivos que los seres humanos para propagar la enfermedad, ya que suelen tenderse en áreas fácilmente accesibles a los triatomineos ${ }^{1}$. Por otro lado existe una alta probabilidad de que animales domésticos experimenten numerosas reinfestaciones, resultando alarmante al considerar que las reinfestaciones experimentales aumentan la parasitemia en perros, monos y ratones ${ }^{14,17}$. Además hay que considerar otros factores tales como la posibilidad de que los caninos exploren áreas infestadas para luego regresar al hogar como portadores del parásito ${ }^{11}$.

La enfermedad de Chagas evoluciona en tres fases: aguda, indeterminada y crónica, cada una de ellas con características clínicas y criterios diagnósticos y terapéuticos diferentes ${ }^{3}$. Si bien en los animales silvestres la afección transcurre en forma clínicamente inaparente, en el perro -en cambio- es a veces sintomática, similar a la del hombre, observándose una forma aguda y otra crónica. La primera ocurre principalmente en perros menores de un año y se inicia en forma súbita, con signos de insuficiencia cardíaca derecha, previa linfoadenomegalia generalizada ${ }^{13}$.

El período desde la infestación hasta la presentación de la enfermedad aguda es variable ${ }^{13}$ aunque puede instalarse después de 5 a 42 días de incubación ${ }^{1}$. Esta forma se manifiesta por fiebre moderada, con o sin edema palpebral, hepatomegalia, adenopatías, alteraciones cardíacas y nerviosas ${ }^{1}$. Los perros que no mueren en forma súbita por la insuficiencia cardíaca, presentan ascitis, hepato y esplenomegalia, pudiendo también padecer anorexia y diarrea. Perros con infección natural y experimental presentaron signos neurológicos referibles a meningoencefalitis, que incluyen ataxia de los miembros pélvicos, debilidad profunda y reflejos espinales hiperactivos ${ }^{13}$.

La forma aguda dura de 10 a 30 días o más y pasa luego a una forma indeterminada que puede prolongarse por años sin manifestaciones clínicas ${ }^{1}$. En la forma crónica se observa miocarditis con dilatación cardíaca en los 8 a 36 meses siguientes. En perros se han reproducido experimentalmente las cardiopatías, megalovísceras y alteraciones del sistema nervioso central ${ }^{1}$. En perros, el megaesófago secundario se debe asociar a una infestación por T. cruzi $^{12}$.

En latinoamérica el perro juega un papel muy importante en la transmisión de $T$. cruzi domiciliar, pues constituye un reservorio altamente infectante para el vector ${ }^{10}$. Asímismo, el índice de infección del vector con el parásito aumenta con respecto al número de perros infectados. El perro puede ser también víctima del parásito, ya que puede sufrir la enfermedad al igual que los seres humanos ${ }^{1}$.

El objetivo de esta comunicación es presentar un caso de tripanosomiasis americana registrado en la especie canina, cuyo diagnóstico fue confirmado por métodos parasitológicos, serológicos y moleculares, a fines del año 2014 en la Provincia de Chaco, Argentina.

\section{Presentación del caso}

El paciente fue una perra doméstica de raza indefinida, de aproximadamente 18 meses de edad, que arribó a la consulta por presentar vómitos incoercibles, diarrea sanguinolenta y deshidratación. Registraba una temperatura de $39,2^{\circ} \mathrm{C}$, deshidratación severa, linfoadenomegalia generalizada, edema en las extremidades y petequias en la mucosa bucal (Figura 1).

A la anamnesis los responsables de la mascota manifestaron un comienzo súbito iniciado dos días anteriores, caracterizado por anorexia, aumento de la temperatura corporal y postración. En primera instancia el objetivo terapéutico se concentró en estabilizar al paciente instaurando una terapia de sostén y tratamiento sintomatológico. Mientras se analizaban muestras extraídas con fines diagnósticos el canino fue hospitalizado, recibiendo cuidados intensivos y monitoreo constante, no obstante lo cual murió a los dos días.

\section{Diagnóstico}

Se procedió a la extracción de sangre venosa, con y sin anticoagulante (EDTA). El suero obtenido se mantuvo refrigerado a $4^{\circ} \mathrm{C}$. Con sangre periférica proveniente del pabellón auricular se realizaron extendidos sanguíneos (frotis), que luego de ser fijados con metanol se colorearon con Giemsa para su observación

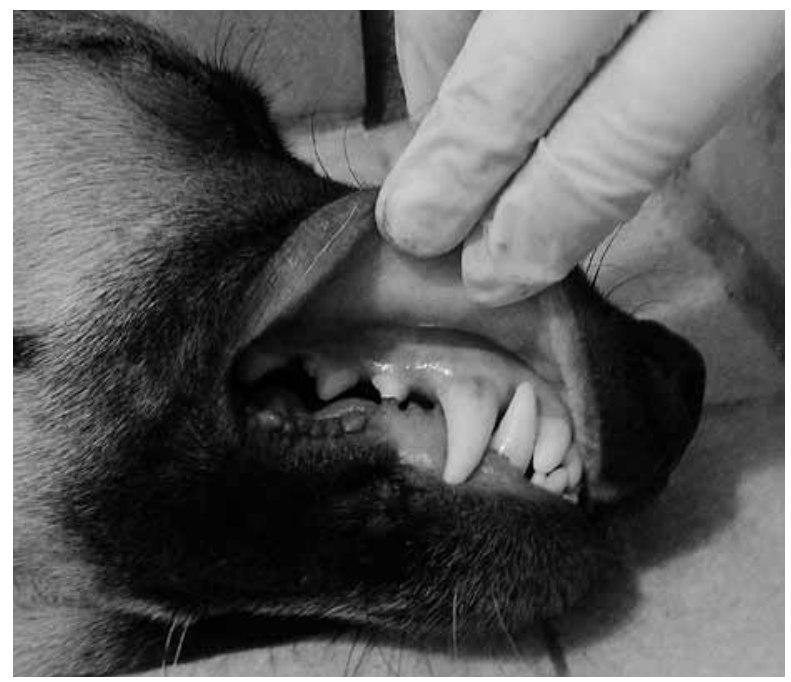

Figura 1. Petequias en la mucosa bucal, coexistentes con fiebre y linfoadenomegalia. 


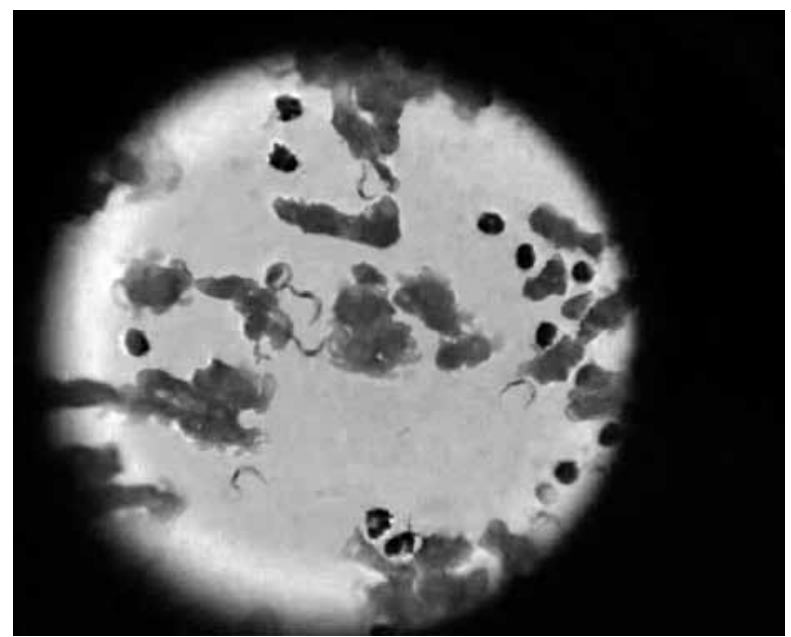

Figura 2. Parásitos extracelulares morfológicamente compatibles con Trypanosoma sp. Giemsa, 200x.

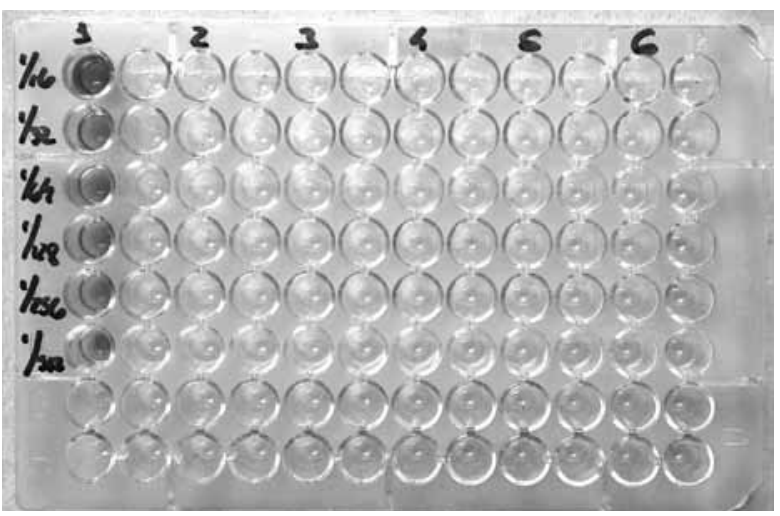

Figura 3. Prueba de hemoaglutinación indirecta (HAI) positiva para Chagas (dilución 1/256).

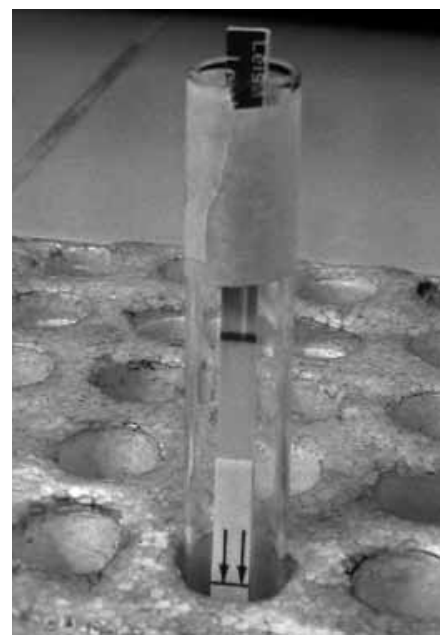

Figura 4. Negatividad de tira reactiva rK39 para determinación serológica de Leishmania sp.

microscópica, la cual reveló la presencia de parásitos sanguíneos extracelulares (Figura 2) compatibles con el estadio de tripomastigote de Trypanosoma $s p$.

Con el diagnóstico presuntivo de tripanosomiasis americana, se efectuó la confirmación etiológica a través de la prueba serológica de hemoaglutinación indirecta (HAI), realizándose diluciones seriadas para el suero, considerándose presumiblemente parasitados aquellos sueros con reactividad en diluciones mayores o iguales a 1/16 según lo estipulado por la OMS. Se empleó el kit Chagatest HAI (Wiener Lab). El suero mostró reactividad para mal de Chagas, revelando la formación de una malla de bordes irregulares que cubría el $50-100 \%$ del fondo de los pocillos para la dilución 1/256 (Figura 3). El suero también se confrontó con la tira reactiva rK39 Kala Asar Detec para investigar la existencia de leishmaniasis (Figura 4), la cual resultó negativa.

Por último, se decidió efectuar la técnica de reacción en cadena de la polimerasa (PCR), dado que permite detectar un parásito o un fragmento de ADN de $T$. cruzi en $20 \mathrm{ml}$ de sangre ${ }^{6}$. Para ello se remitió material al Instituto de Patología Experimental de la Provincia de Salta, cuyo informe corroboró la presencia de Trypanosoma cruzi.

\section{Colofón}

Los caninos están involucrados de manera significativa en el ciclo de transmisión y mantenimiento del mal de Chagas, como reservorios y como huéspedes potenciales de la enfermedad, por lo cual deben ser considerados centinelas en los programas de vigilancia epidemiológica.

La vigilancia de la tripanosomiasis americana con una franca orientación ecosistémica, tiende a generar una visión integral de la situación actual y convertirse en una herramienta muy valiosa en la toma de decisiones en los programas de lucha y control.

\section{Referencias}

1. Acha P, Cifres B. 1986. Zoonosis y enfermedades transmisibles comunes al hombre y a los animales, 2da. ed., Publ.OMS, Washington, p. 590-602.

2. Albuquerque R, Barretto M. 1968. Studies on wild reservoirs and vectors of Trypanosoma cruzi. Rev Bras Biol 28: 457-468.

3. Andrade SG. 2000. Patología experimental da doença de Chagas. In: Tripanosoma cruzi e doença de Chagas (Brener Z, Andrade ZA, Barral-Neto MT, ed.), 2 ${ }^{\mathrm{a}}$ ed., Guanabara-Koogan, Río de Janeiro, p. 186-200.

4. Barretto M, Ribeiro R. 1979. Reservatórios silvestres do Trypanosoma (Schizotrypanum) cruzi Chagas 1909. Rev Inst Adolfo Lutz 39: 25-36.

5. Binda J, Trova G, Alonso M, Pereyra R, Sánchez Negrette O. 2014. Presencia de infección por Trypanosoma cruzi y Toxoplasma gondii en caninos de localidades de la Provincia de Salta. Anales III Congreso Panamericano de Zoonosis, La Plata, Argentina, p. 50.

6. Britto C, Silveira C, Cardoso MA, Marques P, Luquetti A, Macedo V, Fernandes O. 2001. Parasite persistence in treated chagasic patients revealed by xenodiagnosis and polimerase chain reaction. Mem Inst Oswaldo Cruz 96: 823-826.

7. Brusés BL, Lucero H, Gorodner JO. 2001. Utilidad de la técnica de PCR en el diagnóstico de la enfermedad de 
Chagas. Anales de Comunicaciones Cientificas y Tecnológicas, Universidad Nacional del Nordeste, Corrientes, p. 117.

8. Cardinal MV, Castañera MB, Lauricella MA, Cecere MC, Ceballos LA, Vazquez GM, Kitron U, Gürtler RE. 2006. A prospective study of the effects of sustained vector surveillance following community-wide insecticide application on Trypanosome cruzi infection of dogs and cats in rural northwestern Argentina. Am J Trop Med Hyg 75: 753-761.

9. Díaz JC. 2000 Epidemiología. In: Trypanosoma cruzi e doenca de Chagas (Brener Z, Andrade Z, Barral-Netto MT, ed.), $2^{\circ}$ ed., Guanabara, Rio de Janeiro, p. 48-74.

10. Eloy LJ, Lucheis SB. 2012. Hemoculture and polymerase chain reaction using primers TCZ1/TCZ2 for the diagnosis of canine and feline trypanosomiasis. ISRN Vet Sci 12: 419-378.

11. Enriquez GF, Cardinal MV, Orozco MM, Lanati L, Schijman AG, Gürtler RE. 2013. Discrete typing units of Trypanosoma cruzi identified in rural dogs and cats in the humid Argentinean Chaco. Parasitology 140: 303-308.

12. Ettinger S, Feldman E. 1997. Tratado de Medicina Interna Veterinaria: Enfermedades del Perro y el Gato, $4^{\circ}$ ed., Ed. InterMédica, Buenos Aires, p. 1363-1364.

13. Greene C. 2000. Enfermedades Infecciosas en Perros $y$ Gatos, $2^{\circ}$ ed., Ed. McGraw-Hill Interamericana, México DF, p. 490-495.
14. Gürtler R, Cecere M, Lauricella M, Cardinal M, Kitron U, Cohen J. 2007. Domestic dogs and cats as sources of Trypanosoma cruzi infection in rural northwestern Argentina. Parasitol 134: 69-82.

15. Gürtler RE, Cecere MC, Vázquez GM, Ceballos LA, Gurevitz JM, Fernández M, Kitron U, Cohen JE. 2014. Domestic animal hosts strongly influence humanfeeding rates of the Chagas disease vector Triatoma infestans in Argentina. PLoS Negl Trop Dis 8: 2894.

16. Kirchhoff LV. 1993. American trypanosomiasis (Chagas disease): a tropical disease now in the United States. $N$ Engl J Med 9: 639-644.

17. Machado EM, Fernandes AJ, Murta SM, Vitor RW, Pinheiro SW, Lopes ER, Adad SJ, Romanha AJ, Dias J. 2001. A study of experimental reinfection by tripanosoma cruzi in dogs. Am J Trop Med Hyg 65: 958-965.

18. Moreno EA, Araujo M, Alarcón ME, Yarbuh A, Araujo S, Borges R. 2006. Efectos de la infección chagásica aguda en ratas Wistar gestantes. Rev Cientif FCV-LUZ 16: 506-516.

19. Reithinger R, Ceballos LA, Stariolo R, Davies CR, Gürtler RE. 2005. Chagas disease control: deltamethrintreated collars reduce Triatoma infestans feeding success on dogs. Trans Royal Soc Trop Med Hyg 99: 502-508.

20. Silveira AC. 2002. O controle da doença de Chagas nos países do cone sul da América. História de uma iniciativa internacional, 1991-2001. Publ. Pan American Health Organization, Washington, p. 15-44. 